Portland State University

PDXScholar

$12-29-2017$

\title{
The Effect of Rare Variants in TREM2 and PLD3 on Longitudinal Cognitive Function in the Wisconsin Registry for Alzheimer's Prevention
}

\author{
Corinne D. Engelman \\ University of Wisconsin School of Medicine and Public Health \\ Burcu F. Darst \\ University of Wisconsin School of Medicine and Public Health \\ Murat Bilgel \\ National Institute on Aging \\ Eva Vasiljevic \\ University of Wisconsin School of Medicine and Public Health \\ Rebecca L. Kosçik \\ 集llow this and additional works at:https://pdxscholar.library.pdx.edu/mth_fac \\ Part of the Longitudinal Data Analysis and Time Series Commons, Nervous System Diseases \\ Commons, and the Neurosciences Commons \\ reepextrageforadditional authors
}

\section{Citation Details}

Engelman, Corinne D.; Darst, Burcu F.; Bilgel, Murat; Vasiljevic, Eva; Koscik, Rebecca L.; Jedynak, Bruno M.; and Johnson, Sterling C., "The Effect of Rare Variants in TREM2 and PLD3 on Longitudinal Cognitive Function in the Wisconsin Registry for Alzheimer's Prevention" (2017). Mathematics and Statistics Faculty Publications and Presentations. 205.

https://pdxscholar.library.pdx.edu/mth_fac/205

This Post-Print is brought to you for free and open access. It has been accepted for inclusion in Mathematics and Statistics Faculty Publications and Presentations by an authorized administrator of PDXScholar. Please contact us if we can make this document more accessible: pdxscholar@pdx.edu. 


\section{Authors}

Corinne D. Engelman, Burcu F. Darst, Murat Bilgel, Eva Vasiljevic, Rebecca L. Koscik, Bruno M. Jedynak, and Sterling C. Johnson 
The effect of rare variants in TREM2 and PLD3 on longitudinal cognitive function in the Wisconsin Registry for Alzheimer's Prevention

Corinne D. Engelman ${ }^{\mathrm{a}, \mathrm{b}, \mathrm{c}, *}$, Burcu F. Darst ${ }^{\mathrm{a}}$, Murat Bilgel ${ }^{\mathrm{d}}$, Eva Vasiljevic ${ }^{\mathrm{a}}$, Rebecca L. Koscik ${ }^{\mathrm{b}}$, Bruno M. Jedynak ${ }^{\mathrm{e}}$, Sterling C. Johnson ${ }^{\mathrm{b}, \mathrm{c}, \mathrm{f}}$

a Department of Population Health Sciences, University of Wisconsin School of Medicine and Public Health, 610 Walnut Street, 707 WARF, Madison, WI 53726, USA; ${ }^{\text {b Wisconsin }}$ Alzheimer's Institute, University of Wisconsin School of Medicine and Public Health, 610

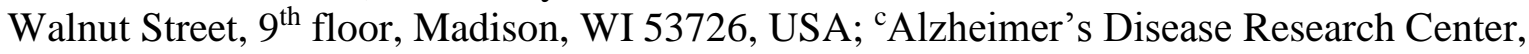
University of Wisconsin School of Medicine and Public Health, 600 Highland Avenue, J5/1 Mezzanine, Madison, WI 53792 ,USA; ' ${ }^{2}$ aboratory of Behavioral Neuroscience, National Institute on Aging, NIH, Baltimore, MD 21224, USA; 'Department of Mathematics and Statistics, Portland State University, 724 SW Harrison Street, Portland, OR 97201, USA; ${ }^{\mathrm{f}}$ Geriatric Research Education and Clinical Center, Wm. S. Middleton Memorial VA Hospital, 2500 Overlook Terrace, Madison, WI 53705, USA.

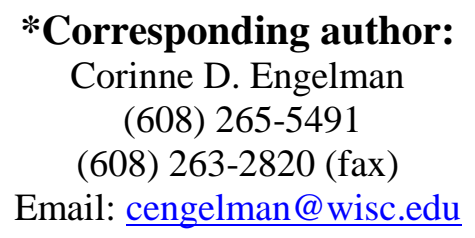

\begin{abstract}
Recent studies have found an association between functional variants in TREM2 and PLD3 and Alzheimer's disease (AD), but their effect on cognitive function is unknown. We examined the effect of these variants on cognitive function in 1,449 participants from the Wisconsin Registry for Alzheimer's Prevention, a longitudinal study of initially asymptomatic adults, age 36-73 at baseline, enriched for a parental history of AD. A comprehensive cognitive test battery was performed at up to five visits. A factor analysis resulted in six cognitive factors that were standardized into $z$ scores $(\sim \mathrm{N}[0,1])$; the mean of these $z$ scores was also calculated. In linear mixed models adjusted for age, gender, practice effects, and self-reported race/ethnicity, PLD3 V232M carriers had significantly lower mean z scores $(p=0.02)$, and lower z scores for Story Recall $(p=0.04)$, Visual Learning \& Memory $(p=0.0 \underline{49})$, and Speed \& Flexibility $(p=0.0 \underline{2}) \underline{\text { than }}$ non-carriers. TREM2 R47H carriers had marginally lower $z$ scores for Speed \& Flexibility
\end{abstract}


( $p=0.06$ ). In conclusion, a functional variant in PLD3 was associated with significantly lower cognitive function in individuals carrying the variant than in non-carriers.

Keywords: TREM2, PLD3, family history, Alzheimer's disease, memory, cognition, longitudinal

\section{Introduction}

Alzheimer's disease (AD) is the most common form of dementia, accounting for $60-80 \%$ of dementia cases. Over 5 million Americans have AD and that number is expected to increase to nearly 14 million by 2050 due to the projected increase in the number of older Americans (Alzheimer's Association, 2016). AD is the sixth leading cause of death in the United States and the only of the top ten causes of death with no way to prevent, cure, or impede its progression (Alzheimer's Association, 2013). There are currently few known risk factors that are highly predictive of $\mathrm{AD}$. Individuals with a family history of $\mathrm{AD}$ are known to be at increased risk for developing the disease, and the $\varepsilon 4$ allele of the apolipoprotein E gene (APOE) is also a wellestablished risk factor. Carrying one copy of the APOE $\varepsilon 4$ allele results in a three-fold higher risk of developing $\mathrm{AD}$ than those with two copies of the more common $\varepsilon 3$ allele, and those with two copies of the $\varepsilon 4$ allele have an 8- to 12-fold higher risk (Holtzman, et al., 2012,Loy, et al., 2014).

Recent genome-wide association studies (GWAS) have identified 19 additional genetic regions that are associated with $\mathrm{AD}$ (Lambert, et al., 2013,Naj, et al., 2011). While potentially important for risk prediction, the genetic variants in these regions are of unknown function and have modest odds ratios (OR) ranging from 1.1 to 1.2 per risk allele. Moreover, these variants 
together explain a relatively small portion of the full genetic contribution to AD (Ridge, et al., 2013). GWAS have typically focused on common genetic variants, with minor allele frequencies $\geq 5 \%$, as these were historically the types of variants included on genome-wide chips. However, recent sequencing studies have identified three functional low frequency (minor allele frequency $0.5-5 \%$ ) variants with a more substantial effect (OR of approximately 2-5) on risk for AD: R47H in the triggering receptor expressed on myeloid cells 2 gene (TREM2) [(Guerreiro, et al., 2012);(Jonsson, et al., 2012)], and V232M and A442A (splice site variant) in the phospholipase D family, member 3 gene (PLD3) (Cruchaga, et al., 2013). We sought to examine the effect of these variants on cognitive performance in a longitudinal study of middle-aged adults who were cognitively healthy at enrollment and enriched for a parental history of AD.

\section{Methods}

\subsection{Study population}

Study participants were from the Wisconsin Registry for Alzheimer's Prevention (WRAP), a longitudinal study of initially asymptomatic adults, age 36-73 at baseline, that allows for the enrollment of siblings and is enriched for a parental history of AD (i.e., a biological parent with either autopsy-confirmed AD, probable AD as defined by NINCDS-ADRDA research criteria (McKhann, et al., 1984), or dementia due to AD based on the Dementia Questionnaire (DQ) (Ellis, et al., 1998)). Details of the study design and methods have been previously described (Engelman, et al., 2014,La Rue, et al., 2008,Sager, et al., 2005). Baseline recruitment began in 2001 with initial follow up after four years and subsequent ongoing follow up every two years or until a participant receives a clinical diagnosis of $\mathrm{AD}$, at which point they are no longer followed. Data from up to five study visits were available for the current analyses. A total of 
1,449 WRAP participants had genotypic data for the low frequency variants analyzed in the current study. This study was conducted with the approval of the University of Wisconsin Institutional Review Board and all subjects provided signed informed consent before participation.

\subsection{Neuropsychological assessment}

The WRAP cognitive test battery assesses many domains and has been previously described (Darst, et al., 2015,Sager, et al., 2005). For these analyses, we used one composite variable estimating cognitive functioning at age 54 (the mean age at baseline) and six factor scores representing longitudinal functioning across memory and executive function domains.

\subsubsection{Composite Progression Score}

A composite index, named progression score (PS), was computed using a set of eight cognitive measures, including Trails A and B (Reitan and Wolfson, 1985), Digit Span Forward and Digit Span Backward (Wechsler, 1997), Rey Auditory Verbal Learning Test (AVLT) summed score across five learning trials (Lezak, et al., 2004), AVLT delayed recall (Lezak, et al., 2004), Boston Naming Test (Kaplan, et al., 1983), and the Mini-Mental State Examination (Folstein, et al., 1975). Visits with fewer than four of these measurements were excluded. We applied the PS model (Bilgel, et al., 2015,Jedynak, et al., 2012) to align individuals along a linear cognitive trajectory based on their longitudinal cognitive measure profiles, adjusting for inter-individual differences in rates of change, with a higher PS indicating greater overall cognitive decline across the eight measures. We accounted for correlations among cognitive measures and constrained the progression scores to increase linearly with age within each individual. To remove confounding effects of age at entry into WRAP, the progression score was estimated at age 54, the mean age at baseline. 


\subsubsection{Longitudinal Factor Scores}

A factor analysis of the neuropsychological test scores was performed as described previously

(Dowling, et al., 2010,Jonaitis, et al., 2015,Koscik, et al., 2014). The resulting factor scores were standardized into $z$ scores $(\sim \mathrm{N}[0,1])$, using means and standard deviations obtained from the whole sample at baseline (visit 1) or visit 2 for a subset of tests that were first administered at this visit. There were four cognitive factor $z$ scores for memory (Immediate Memory, Verbal Learning \& Memory, Story Recall, and Visual Learning \& Memory) and two for executive function (Working Memory and Speed \& Flexibility). Tests comprising each of these factors have been previously described (Darst, et al., 2015). Due to the small number of individuals carrying the functional variants, these six factor scores were also averaged to create a summary $\underline{\text { cognitive measure of the factor scores for each individual. Consequently, we did not adjust for }}$ multiple comparisons when examining the mean $z$ score and used the individual cognitive factor scores to inform which domains were driving the association with the mean $z$ score.

\subsection{DNA Collection, Genotyping, and Quality Control}

DNA was extracted from whole blood samples as described previously (Engelman, et al., 2013). Genotyping of the TREM2 variant $\mathrm{R} 47 \mathrm{H}$ (rs75932628) and PLD3 variants V232M (rs145999145) and A442A (rs4819; splice site variant) was performed using competitive allelespecific PCR based KASP ${ }^{\mathrm{TM}}$ genotyping assays (LGC Genomics, Beverly, MA). The quality control process has been described previously (Darst, et al., 2016). The PLD3 splice site variant, A442A, was monomorphic in our sample. Consequently, no genetic association analysis could be performed on this variant. The other PLD3 variant and the TREM2 variant were in HardyWeinberg equilibrium.

\subsection{Statistical analysis}


Differences in allele frequencies between those with a parental history of $\mathrm{AD}$ and those without were tested using a Fisher's exact test. TREM2 and PLD3 associations with each of the cognitive factor scores and the PS at age 54 were tested using linear mixed models (SAS PROC MIXED) by comparing carriers of one of the rare variants to non-carriers of either. For each cognitive factor score, models included fixed effects for age, gender, practice effects, and self-reported race/ethnicity and random effects for family (siblings) and participant (repeated measures). For the PS, the model included fixed effects for gender and race/ethnicity (age was not adjusted for as it was used to calculate the PS) and a random effect for family. To visually display the cognitive factor $\mathrm{z}$ scores, adjusted mean $z$ scores (a weighted average of the predicted $z$ scores across all classes of gender and race/ethnicity, and for the average age) were calculated and plotted for TREM2 R47H and PLD3 V232M carriers, as well as for APOE $\varepsilon 4$ homozygotes, $\varepsilon 4$ heterozygotes, and non-carriers of any of these three risk variants, using the LSMEANS statement in PROC MIXED with the OM option to weight the average of the predictions to be proportionate to the input data set. This was especially important for race/ethnicity, which was not evenly distributed in the WRAP cohort. All analyses were performed in SAS v9.4 and used a $p$ value threshold of $<0.05$ to determine significance.

\section{Results}

Characteristics of the 1,449 participants, according to TREM2 and PLD3 carrier status, are shown in Table 1. No participants carried both the TREM2 R47H (T allele) and PLD3 V232M (A allele) low frequency variants. There were no significant $(p<0.05)$ differences in the characteristics between carriers of either variant and non-carriers. Of the 16 participants who 
carried the TREM2 variant, 15 were non-Hispanic Caucasian, 1 was Hispanic, and none were African American or another race/ethnicity. All 13 PLD3 carriers were non-Hispanic Caucasian.

Presence of the TREM2 R47H variant was associated with AD parental history status; all sixteen participants with $\mathrm{R} 47 \mathrm{H}$ were in the parental history group (Table 2). Patterns appeared similar for the relationship between PLD3 V232 2 and AD parental history.

In linear mixed models, $P L D 3$ carriers had significantly lower mean z scores, and lower $z$ scores for Story Recall, Visual Learning \& Memory, and Speed \& Flexibility than non-carriers

(Table 3; results for $A P O E \& 4$ count are shown for comparison). TREM2 carriers had marginally lower $z$ scores for Speed \& Flexibility $(p=0.06)$. While the PS at age 54 was higher for both TREM2 and PLD3 carriers, indicating greater disease progression, these differences were not statistically significant. Adjusted mean $z$ scores for the six cognitive factors for TREM2 carriers, PLD3 carriers, as well as for APOE $\varepsilon 4$ homozygotes, $\varepsilon 4$ heterozygotes, and non-carriers of any of these three risk variants are shown in Figure 1.

\section{Discussion}

Functional low frequency variants in TREM2 are established risk factors for AD and an additional variant in PLD3 has been reported (Cruchaga, et al., 2013), but their effect on cognitive function in the years prior to the typical onset of $\mathrm{AD}$ is unknown. We examined the effect of these variants on cognitive performance in a longitudinal study of middle-aged adults who were cognitively healthy at enrollment, the majority of whom had a parental history of AD. The TREM2 R47H variant was found in 15 non-Hispanic Caucasians and 1 Hispanic, all with a parent who had AD. The PLD3 V232M variant was only found in non-Hispanic Caucasians and was twice as common in individuals with a parental history of AD than in those without a 
parental history. Although both variants were generally associated with lower cognitive function in carriers of either variant than in non-carriers, only carriers of the PLD3 variant had significantly lower cognitive function than non-carriers.

Our study population was intentionally enriched for individuals with a parental history of $\mathrm{AD}(72 \%$ of participants). While the carrier percentages in the parental history group were $1.5 \%$ for TREM2 R47H (T allele) and $1.1 \%$ for PLD3 V232M (A allele), the percentages in the participants with no parental history of $\mathrm{AD}$ were $0 \%$ and $0.5 \%$, respectively. The TREM2 R47H carrier percentage is $0.4 \%$ in the Exome Aggregation Consortium database (ExAC; $N=60,145$; accessed 11/15/16) (Lek, et al., 2016) and 0.5\% in the Genome Aggregation Database (gnomAD; $N=140,485 ;$ beta mode available at http://gnomad.broadinstitute.org; accessed 11/15/16; includes samples from the Alzheimer's Disease Sequencing Project and from ExAC). The PLD3 V232M carrier percentage was $0.6 \%$ in $\operatorname{ExAC}(N=57,683)$ and $0.7 \%$ in gnomAD $(N=$ 141,023). Taken together, for both variants, the percent of individuals carrying the low frequency risk variant was higher in WRAP participants with a parental history of AD than in WRAP participants without a family history or in publicly available reference databases, illustrating the statistical power to be gained from a study design focusing on individuals with a family history of $\mathrm{AD}$, in which low frequency risk variants are likely to be more prevalent.

Our cohort is $89 \%$ non-Hispanic Caucasian, with only 113 African Americans and 34 Hispanics, however, despite these small sample sizes, we did observe one Hispanic carrier of the TREM2 R47H variant. In gnomAD, the largest compilation of large-scale sequencing projects, the TREM2 R47H (T allele) was carried by $0.7 \%$ of Latinos $(n=18,221), 0.5 \%$ of Europeans (non-Finnish; $n=62,674)$, and $0.1 \%$ of Africans $(n=12,921)$. This higher carrier frequency in Latinos and lower carrier frequency in Africans is consistent with our observation. Moreover, 
our lack of PLD3 V232M (A allele) carriers in any group other than non-Hispanic Caucasian is not surprising given that the carrier percentage in gnom $\mathrm{AD}$ for this variant is 2.5 to 5 times higher for Europeans (non-Finnish; $1 \%$ ) than for Latinos $(0.4 \%)$ or Africans $(0.2 \%)$.

PLD3 V232M carriers (six of whom were APOE $\varepsilon 4$ heterozygotes [Table 1]) had least square mean (predicted) cognitive $z$ scores that were lower than both APOE $\varepsilon 4$ heterozygotes and homozygotes across all six cognitive factors (Figure 1). This suggests that the effect of the PLD3 $\mathrm{V} 232 \mathrm{M}$ variant on cognition may be even stronger than carrying two copies of the APOE $\varepsilon 4$ allele. However, this requires replication in other longitudinal studies of cognitive function. Although our findings show consistency across multiple cognitive factors, many of our findings were not statistically significant, and those that were would not survive a correction for multiple testing. This is likely due to the rarity of the variants assessed, but could also be because our relatively young (early 50's at baseline) population may not yet have experienced enough cognitive decline. It will be crucial to validate these findings with an external population, particularly one that has a larger number of carriers for these rare variants. Further, in order to determine how these variants influence the pathology of $\mathrm{AD}$, it will also be essential to evaluate their influence on $\beta$-amyloid and tau, as the accumulation of both occurs long before an AD diagnosis.

In conclusion, our results support previous findings that show an increased AD risk in carriers of low frequency functional variants in TREM2 and PLD3 by suggesting that these variants may also be associated with lower cognitive function, likely due to an AD trajectory. This is particularly notable for the rare PLD3 variant, which is a less established AD risk factor. While these functional variants are found at low frequencies in the population, their effect on risk for $\mathrm{AD}$ is much larger than common variants found through GWAS. In fact, their effect on 
cognition may be similar to, if not greater than, that of the $A P O E \varepsilon 4$ allele. Further research is necessary in order to assess the influence of these rare variants on other crucial neurological changes such as the accumulation of $\beta$-amyloid and tau that are biomarkers of AD pathology.

\section{Acknowledgements}

The WRAP program is funded by National Institute on Aging grants 5R01-AG27161-2

(Wisconsin Registry for Alzheimer's Prevention: Biomarkers of Preclinical AD) and R01AG054047-01 (Genomic and Metabolomic Data Integration in a Longitudinal Cohort at Risk for Alzheimer's Disease), the Helen Bader Foundation, Northwestern Mutual Foundation, Extendicare Foundation, and the Clinical and Translational Science Award (CTSA) program through the NIH National Center for Advancing Translational Sciences (NCATS) grant UL1TR000427. This research was supported in part by the Intramural Research Program of the National Institute on Aging. BFD was supported by an NLM training grant to the Computation and Informatics in Biology and Medicine Training Program grant NLM 5T15LM007359. Computational resources were supported by a core grant to the Center for Demography and Ecology at the University of Wisconsin-Madison (P2C HD047873).

\section{Disclosure statement}

The authors have no actual or potential conflicts of interest to disclose.

\section{References}

Alzheimer's Association. 2013. Alzheimer's Disease Facts and Figures. Alzheimer's \& Dementia 9(2), 208-45.

Alzheimer's Association. 2016. 2016 Alzheimer's disease facts and figures. Alzheimers Dement 12(4), 459-509. 
Bilgel, M., Jedynak, B., Wong, D.F., Resnick, S.M., Prince, J.L. 2015. Temporal Trajectory and Progression Score Estimation from Voxelwise Longitudinal Imaging Measures: Application to Amyloid Imaging. Information processing in medical imaging : proceedings of the conference 24, 424-36.

Cruchaga, C., Karch, C.M., Jin, S.C., Benitez, B.A., Cai, Y., Guerreiro, R., Harari, O., Norton, J., Budde, J., Bertelsen, S., Jeng, A.T., Cooper, B., Skorupa, T., Carrell, D., Levitch, D., Hsu, S., Choi, J., Ryten, M., Hardy, J., Trabzuni, D., Weale, M.E., Ramasamy, A., Smith, C., Sassi, C., Bras, J., Gibbs, J.R., Hernandez, D.G., Lupton, M.K., Powell, J., Forabosco, P., Ridge, P.G., Corcoran, C.D., Tschanz, J.T., Norton, M.C., Munger, R.G., Schmutz, C., Leary, M., Demirci, F.Y., Bamne, M.N., Wang, X., Lopez, O.L., Ganguli, M., Medway, C., Turton, J., Lord, J., Braae, A., Barber, I., Brown, K., Passmore, P., Craig, D., Johnston, J., McGuinness, B., Todd, S., Heun, R., Kolsch, H., Kehoe, P.G., Hooper, N.M., Vardy, E.R., Mann, D.M., Pickering-Brown, S., Kalsheker, N., Lowe, J., Morgan, K., David Smith, A., Wilcock, G., Warden, D., Holmes, C., Pastor, P., Lorenzo-Betancor, O., Brkanac, Z., Scott, E., Topol, E., Rogaeva, E., Singleton, A.B., Kamboh, M.I., St George-Hyslop, P., Cairns, N., Morris, J.C., Kauwe, J.S., Goate, A.M. 2013. Rare coding variants in the phospholipase D3 gene confer risk for Alzheimer's disease. Nature. doi:10.1038/nature12825.

Darst, B.F., Koscik, R.L., Hermann, B.P., La Rue, A., Sager, M.A., Johnson, S.C., Engelman, C.D. 2015. Heritability of Cognitive Traits Among Siblings with a Parental History of Alzheimer's Disease. J Alzheimers Dis. doi:10.3233/JAD-142658.

Darst, B.F., Koscik, R.L., Racine, A.M., Oh, J.M., Krause, R.A., Carlsson, C.M., Zetterberg, H., Blennow, K., Christian, B.T., Bendlin, B.B., Okonkwo, O.C., Hogan, K.J., Hermann, B.P., Sager, M.A., Asthana, S., Johnson, S.C., Engelman, C.D. 2016. Pathway-Specific Polygenic Risk Scores as Predictors of Amyloid-beta Deposition and Cognitive Function in a Sample at Increased Risk for Alzheimer's Disease. J Alzheimers Dis. doi:10.3233/JAD-160195.

Dowling, N.M., Hermann, B., La Rue, A., Sager, M.A. 2010. Latent structure and factorial invariance of a neuropsychological test battery for the study of preclinical Alzheimer's disease. Neuropsychology 24(6), 742-56. doi:10.1037/a0020176.

Ellis, R.J., Jan, K., Kawas, C., Koller, W.C., Lyons, K.E., Jeste, D.V., Hansen, L.A., Thal, L.J. 1998. Diagnostic validity of the dementia questionnaire for Alzheimer disease. Archives of neurology 55(3), 360-5.

Engelman, C.D., Koscik, R.L., Jonaitis, E.M., Hermann, B.P., La Rue, A., Sager, M.A. 2014. Investigation of triggering receptor expressed on myeloid cells 2 variant in the Wisconsin Registry for Alzheimer's Prevention. Neurobiology of aging 35(6), 1252-4. doi:10.1016/j.neurobiolaging.2013.11.013.

Engelman, C.D., Koscik, R.L., Jonaitis, E.M., Okonkwo, O.C., Hermann, B.P., La Rue, A., Sager, M.A. 2013. Interaction Between Two Cholesterol Metabolism Genes Influences Memory: Findings from the Wisconsin Registry for Alzheimer's Prevention. J Alzheimers Dis. doi:10.3233/JAD-130482.

Folstein, M.F., Folstein, S.E., McHugh, P.R. 1975. "Mini-mental state". A practical method for grading the cognitive state of patients for the clinician. Journal of psychiatric research 12(3), 189-98.

Guerreiro, R., Wojtas, A., Bras, J., Carrasquillo, M., Rogaeva, E., Majounie, E., Cruchaga, C., Sassi, C., Kauwe, J.S., Younkin, S., Hazrati, L., Collinge, J., Pocock, J., Lashley, T., 
Williams, J., Lambert, J.C., Amouyel, P., Goate, A., Rademakers, R., Morgan, K., Powell, J., St George-Hyslop, P., Singleton, A., Hardy, J. 2012. TREM2 Variants in Alzheimer's Disease. The New England journal of medicine. doi:10.1056/NEJMoa1211851.

Holtzman, D.M., Herz, J., Bu, G. 2012. Apolipoprotein E and apolipoprotein E receptors: normal biology and roles in Alzheimer disease. Cold Spring Harb Perspect Med 2(3), a006312. doi:10.1101/cshperspect.a006312.

Jedynak, B.M., Lang, A., Liu, B., Katz, E., Zhang, Y., Wyman, B.T., Raunig, D., Jedynak, C.P., Caffo, B., Prince, J.L., Alzheimer's Disease Neuroimaging, I. 2012. A computational neurodegenerative disease progression score: method and results with the Alzheimer's disease Neuroimaging Initiative cohort. NeuroImage 63(3), 1478-86. doi:10.1016/j.neuroimage.2012.07.059.

Jonaitis, E.M., Koscik, R.L., La Rue, A., Johnson, S.C., Hermann, B.P., Sager, M.A. 2015. Aging, Practice Effects, and Genetic Risk in the Wisconsin Registry for Alzheimer's Prevention. Clin Neuropsychol 29(4), 426-41. doi:10.1080/13854046.2015.1047407.

Jonsson, T., Stefansson, H., Ph, D.S., Jonsdottir, I., Jonsson, P.V., Snaedal, J., Bjornsson, S., Huttenlocher, J., Levey, A.I., Lah, J.J., Rujescu, D., Hampel, H., Giegling, I., Andreassen, O.A., Engedal, K., Ulstein, I., Djurovic, S., Ibrahim-Verbaas, C., Hofman, A., Ikram, M.A., van Duijn, C.M., Thorsteinsdottir, U., Kong, A., Stefansson, K. 2012. Variant of TREM2 Associated with the Risk of Alzheimer's Disease. The New England journal of medicine. doi:10.1056/NEJMoa1211103.

Kaplan, E., Goodglass, H., Weintraub, S. 1983. Boston naming test. Lea \& Febiger, Philadelphia.

Koscik, R.L., La Rue, A., Jonaitis, E.M., Okonkwo, O.C., Johnson, S.C., Bendlin, B.B., Hermann, B.P., Sager, M.A. 2014. Emergence of mild cognitive impairment in late middle-aged adults in the wisconsin registry for Alzheimer's prevention. Dement Geriatr Cogn Disord 38(1-2), 16-30. doi:10.1159/000355682.

La Rue, A., Hermann, B., Jones, J.E., Johnson, S., Asthana, S., Sager, M.A. 2008. Effect of parental family history of Alzheimer's disease on serial position profiles. Alzheimers Dement 4(4), 285-90.

Lambert, J.C., Ibrahim-Verbaas, C.A., Harold, D., Naj, A.C., Sims, R., Bellenguez, C., Jun, G., Destefano, A.L., Bis, J.C., Beecham, G.W., Grenier-Boley, B., Russo, G., ThorntonWells, T.A., Jones, N., Smith, A.V., Chouraki, V., Thomas, C., Ikram, M.A., Zelenika, D., Vardarajan, B.N., Kamatani, Y., Lin, C.F., Gerrish, A., Schmidt, H., Kunkle, B., Dunstan, M.L., Ruiz, A., Bihoreau, M.T., Choi, S.H., Reitz, C., Pasquier, F., Hollingworth, P., Ramirez, A., Hanon, O., Fitzpatrick, A.L., Buxbaum, J.D., Campion, D., Crane, P.K., Baldwin, C., Becker, T., Gudnason, V., Cruchaga, C., Craig, D., Amin, N., Berr, C., Lopez, O.L., De Jager, P.L., Deramecourt, V., Johnston, J.A., Evans, D., Lovestone, S., Letenneur, L., Moron, F.J., Rubinsztein, D.C., Eiriksdottir, G., Sleegers, K., Goate, A.M., Fievet, N., Huentelman, M.J., Gill, M., Brown, K., Kamboh, M.I., Keller, L., Barberger-Gateau, P., McGuinness, B., Larson, E.B., Green, R., Myers, A.J., Dufouil, C., Todd, S., Wallon, D., Love, S., Rogaeva, E., Gallacher, J., St GeorgeHyslop, P., Clarimon, J., Lleo, A., Bayer, A., Tsuang, D.W., Yu, L., Tsolaki, M., Bossu, P., Spalletta, G., Proitsi, P., Collinge, J., Sorbi, S., Sanchez-Garcia, F., Fox, N.C., Hardy, J., Naranjo, M.C., Bosco, P., Clarke, R., Brayne, C., Galimberti, D., Mancuso, M., Matthews, F., Moebus, S., Mecocci, P., Del Zompo, M., Maier, W., Hampel, H., Pilotto, 
A., Bullido, M., Panza, F., Caffarra, P., Nacmias, B., Gilbert, J.R., Mayhaus, M., Lannfelt, L., Hakonarson, H., Pichler, S., Carrasquillo, M.M., Ingelsson, M., Beekly, D., Alvarez, V., Zou, F., Valladares, O., Younkin, S.G., Coto, E., Hamilton-Nelson, K.L., Gu, W., Razquin, C., Pastor, P., Mateo, I., Owen, M.J., Faber, K.M., Jonsson, P.V., Combarros, O., O'Donovan, M.C., Cantwell, L.B., Soininen, H., Blacker, D., Mead, S., Mosley, T.H., Jr., Bennett, D.A., Harris, T.B., Fratiglioni, L., Holmes, C., de Bruijn, R.F., Passmore, P., Montine, T.J., Bettens, K., Rotter, J.I., Brice, A., Morgan, K., Foroud, T.M., Kukull, W.A., Hannequin, D., Powell, J.F., Nalls, M.A., Ritchie, K., Lunetta, K.L., Kauwe, J.S., Boerwinkle, E., Riemenschneider, M., Boada, M., Hiltunen, M., Martin, E.R., Schmidt, R., Rujescu, D., Wang, L.S., Dartigues, J.F., Mayeux, R., Tzourio, C., Hofman, A., Nothen, M.M., Graff, C., Psaty, B.M., Jones, L., Haines, J.L., Holmans, P.A., Lathrop, M., Pericak-Vance, M.A., Launer, L.J., Farrer, L.A., van Duijn, C.M., Van Broeckhoven, C., Moskvina, V., Seshadri, S., Williams, J., Schellenberg, G.D., Amouyel, P. 2013. Meta-analysis of 74,046 individuals identifies 11 new susceptibility loci for Alzheimer's disease. Nature genetics 45(12), 1452-8. doi:10.1038/ng.2802.

Lek, M., Karczewski, K.J., Minikel, E.V., Samocha, K.E., Banks, E., Fennell, T., O'DonnellLuria, A.H., Ware, J.S., Hill, A.J., Cummings, B.B., Tukiainen, T., Birnbaum, D.P., Kosmicki, J.A., Duncan, L.E., Estrada, K., Zhao, F., Zou, J., Pierce-Hoffman, E., Berghout, J., Cooper, D.N., Deflaux, N., DePristo, M., Do, R., Flannick, J., Fromer, M., Gauthier, L., Goldstein, J., Gupta, N., Howrigan, D., Kiezun, A., Kurki, M.I., Moonshine, A.L., Natarajan, P., Orozco, L., Peloso, G.M., Poplin, R., Rivas, M.A., Ruano-Rubio, V., Rose, S.A., Ruderfer, D.M., Shakir, K., Stenson, P.D., Stevens, C., Thomas, B.P., Tiao, G., Tusie-Luna, M.T., Weisburd, B., Won, H.H., Yu, D., Altshuler, D.M., Ardissino, D., Boehnke, M., Danesh, J., Donnelly, S., Elosua, R., Florez, J.C., Gabriel, S.B., Getz, G., Glatt, S.J., Hultman, C.M., Kathiresan, S., Laakso, M., McCarroll, S., McCarthy, M.I., McGovern, D., McPherson, R., Neale, B.M., Palotie, A., Purcell, S.M., Saleheen, D., Scharf, J.M., Sklar, P., Sullivan, P.F., Tuomilehto, J., Tsuang, M.T., Watkins, H.C., Wilson, J.G., Daly, M.J., MacArthur, D.G., Exome Aggregation, C. 2016. Analysis of protein-coding genetic variation in 60,706 humans. Nature 536(7616), 285-91. doi:10.1038/nature19057.

Lezak, M., Howieson, D., Loring, D. 2004. Neuropsychological Assessment. 4 ed. Oxford University Press, New York.

Loy, C.T., Schofield, P.R., Turner, A.M., Kwok, J.B. 2014. Genetics of dementia. Lancet 383(9919), 828-40. doi:10.1016/S0140-6736(13)60630-3.

McKhann, G., Drachman, D., Folstein, M., Katzman, R., Price, D., Stadlan, E.M. 1984. Clinical diagnosis of Alzheimer's disease: report of the NINCDS-ADRDA Work Group under the auspices of Department of Health and Human Services Task Force on Alzheimer's Disease. Neurology 34(7), 939-44.

Naj, A.C., Jun, G., Beecham, G.W., Wang, L.S., Vardarajan, B.N., Buros, J., Gallins, P.J., Buxbaum, J.D., Jarvik, G.P., Crane, P.K., Larson, E.B., Bird, T.D., Boeve, B.F., GraffRadford, N.R., De Jager, P.L., Evans, D., Schneider, J.A., Carrasquillo, M.M., ErtekinTaner, N., Younkin, S.G., Cruchaga, C., Kauwe, J.S., Nowotny, P., Kramer, P., Hardy, J., Huentelman, M.J., Myers, A.J., Barmada, M.M., Demirci, F.Y., Baldwin, C.T., Green, R.C., Rogaeva, E., St George-Hyslop, P., Arnold, S.E., Barber, R., Beach, T., Bigio, E.H., Bowen, J.D., Boxer, A., Burke, J.R., Cairns, N.J., Carlson, C.S., Carney, R.M., Carroll, S.L., Chui, H.C., Clark, D.G., Corneveaux, J., Cotman, C.W., Cummings, J.L., 
DeCarli, C., DeKosky, S.T., Diaz-Arrastia, R., Dick, M., Dickson, D.W., Ellis, W.G., Faber, K.M., Fallon, K.B., Farlow, M.R., Ferris, S., Frosch, M.P., Galasko, D.R., Ganguli, M., Gearing, M., Geschwind, D.H., Ghetti, B., Gilbert, J.R., Gilman, S., Giordani, B., Glass, J.D., Growdon, J.H., Hamilton, R.L., Harrell, L.E., Head, E., Honig, L.S., Hulette, C.M., Hyman, B.T., Jicha, G.A., Jin, L.W., Johnson, N., Karlawish, J., Karydas, A., Kaye, J.A., Kim, R., Koo, E.H., Kowall, N.W., Lah, J.J., Levey, A.I., Lieberman, A.P., Lopez, O.L., Mack, W.J., Marson, D.C., Martiniuk, F., Mash, D.C., Masliah, E., McCormick, W.C., McCurry, S.M., McDavid, A.N., McKee, A.C., Mesulam, M., Miller, B.L., Miller, C.A., Miller, J.W., Parisi, J.E., Perl, D.P., Peskind, E., Petersen, R.C., Poon, W.W., Quinn, J.F., Rajbhandary, R.A., Raskind, M., Reisberg, B., Ringman, J.M., Roberson, E.D., Rosenberg, R.N., Sano, M., Schneider, L.S., Seeley, W., Shelanski, M.L., Slifer, M.A., Smith, C.D., Sonnen, J.A., Spina, S., Stern, R.A., Tanzi, R.E., Trojanowski, J.Q., Troncoso, J.C., Van Deerlin, V.M., Vinters, H.V., Vonsattel, J.P., Weintraub, S., Welsh-Bohmer, K.A., Williamson, J., Woltjer, R.L., Cantwell, L.B., Dombroski, B.A., Beekly, D., Lunetta, K.L., Martin, E.R., Kamboh, M.I., Saykin, A.J., Reiman, E.M., Bennett, D.A., Morris, J.C., Montine, T.J., Goate, A.M., Blacker, D., Tsuang, D.W., Hakonarson, H., Kukull, W.A., Foroud, T.M., Haines, J.L., Mayeux, R., Pericak-Vance, M.A., Farrer, L.A., Schellenberg, G.D. 2011. Common variants at MS4A4/MS4A6E, CD2AP, CD33 and EPHA1 are associated with late-onset Alzheimer's disease. Nature genetics 43(5), 436-41. doi:10.1038/ng.801.

Reitan, R.M., Wolfson, D. 1985. The Halstead-Reitan Neuropsychological Test Battery: Therapy and clinical interpretation. Neuropsychological Press, Tucson, AZ.

Ridge, P.G., Mukherjee, S., Crane, P.K., Kauwe, J.S., Alzheimer's Disease Genetics, C. 2013. Alzheimer's disease: analyzing the missing heritability. PloS one 8(11), e79771. doi:10.1371/journal.pone.0079771.

Sager, M.A., Hermann, B., La Rue, A. 2005. Middle-aged children of persons with Alzheimer's disease: APOE genotypes and cognitive function in the Wisconsin Registry for Alzheimer's Prevention. Journal of geriatric psychiatry and neurology 18(4), 245-9.

Wechsler, D. 1997. Wechsler Adult Intelligence Scale. Psychological Corporation, San Antonio. 
Table 1. WRAP Participant Characteristics at Baseline, Mean (SD) or $n(\%)$

\begin{tabular}{rccc}
\hline & $\begin{array}{c}\text { TREM2 }(\mathbf{R 4 7 H}) \\
\text { Carrier }^{\mathbf{a}} \\
\text { Characteristic }\end{array}$ & $\begin{array}{c}\text { PLD3 }(\mathbf{V 2 3 2 M}) \\
\text { Carrier }^{\mathbf{a}} \\
(\boldsymbol{n}=\mathbf{1 6})\end{array}$ & $\begin{array}{c}\text { Non-carrier } \\
(\boldsymbol{n = 1 , 4 1 3})\end{array}$ \\
\hline $\begin{array}{r}\text { Age (years) } \\
\text { Gender (female) } \\
\text { Race/ethnicity }\end{array}$ & $52.4(5.6)$ & $51.8(8.9)$ & $53.8(6.6)$ \\
Caucasian & $13(81.3)$ & $10(76.9)$ & $898(70.0)$ \\
African American & $15(93.8)$ & $13(100.0)$ & $1,253(88.8)$ \\
Hispanic & 0 & 0 & $113(8.0)$ \\
Other & $1(6.3)$ & 0 & $33(2.3)$ \\
Years of Education & 0 & 0 & $12(0.9)$ \\
APOE Genotype & $15.3(2.8)$ & $15.7(3.1)$ & $16.2(2.3)$ \\
& & & $5(0.4)$ \\
$\varepsilon 2 / \varepsilon 2$ & 0 & 0 & $113(8.0)$ \\
$\varepsilon 2 / \varepsilon 3$ & $1(6.3)$ & $3(23.1)$ & $46(3.3)$ \\
$\varepsilon 2 / \varepsilon 4$ & $1(6.3)$ & 0 & $742(52.5)$ \\
$\varepsilon 3 / \varepsilon 3$ & $6(37.5)$ & $4(30.8)$ & $447(31.6)$ \\
$\varepsilon 3 / \varepsilon 4$ & $7(43.8)$ & $6(46.2)$ & $60(4.2)$ \\
$\varepsilon 4 / \varepsilon 4$ & $1(6.3)$ & 0 &
\end{tabular}

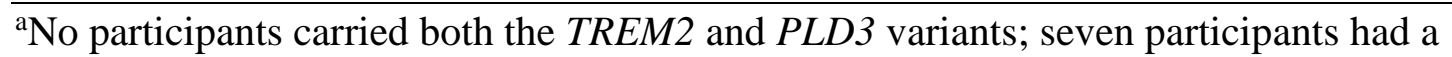
missing genotype for either TREM2 or PLD3 and are not included in this table. Minor/risk allele for TREM2 R47H was T; minor/risk allele for PLD3 V232M was A.

\section{Table 2. Carrier Frequency (n) by Parental History of AD}

\begin{tabular}{lccc}
\hline Gene (variant) & $\begin{array}{c}\text { No parent with AD } \\
(\boldsymbol{n}=\mathbf{4 0 9})\end{array}$ & $\begin{array}{c}\text { Parent with AD } \\
(\boldsymbol{n}=\mathbf{1 0 4 0})\end{array}$ & $\boldsymbol{p}$ value $^{\mathbf{a}}$ \\
\hline TREM2 (R47H) & $0.00(0)$ & $0.015(16)$ & 0.009 \\
PLD3 (V232M) & $0.005(2)$ & $0.011(11)$ & 0.54 \\
\hline
\end{tabular}

'Fisher's exact test of the difference in allele frequency in individuals without versus with a parent with $\mathrm{AD}$. 
Table 3. Association Between Risk Variant and Cognitive Function

\begin{tabular}{|c|c|c|c|}
\hline \multirow[b]{2}{*}{ Cognitive Function } & \multicolumn{3}{|c|}{$\beta \pm S E(p$ value $)$} \\
\hline & $\begin{array}{c}\text { TREM2 (R47H) } \\
(n=1,446)\end{array}$ & $\begin{array}{c}P L D 3 \text { (V232M) } \\
(n=1,445)\end{array}$ & $\underline{A P O E \& 4 \text { count }}$ \\
\hline \multicolumn{4}{|l|}{ Composite Progression Score } \\
\hline Progression Score at age $54^{\mathrm{a}}$ & $0.19 \pm 0.29(0.52)$ & $0.46 \pm 0.33(0.16)$ & $\underline{0.11 \pm 0.05(0.04)}$ \\
\hline \multicolumn{4}{|l|}{ Longitudinal Factor Scores } \\
\hline Mean of six Factor Scores & $-0.14 \pm 0.16(0.38)$ & $-0.41 \pm 0.18(0.02)$ & $-0.10 \pm 0.03(0.002)$ \\
\hline Immediate Memory & $-0.1 \underline{2} \pm 0.2 \underline{0}(0.5 \underline{6})$ & $-0.2 \underline{3} \pm 0.23(0.3 \underline{2})$ & $\underline{-0.07 \pm 0.04(0.06)}$ \\
\hline Verbal Learning \& Memory & $=0.0 \underline{02} \pm 0.22(0.99)$ & $-0.22 \pm 0.25(0 . \underline{37})$ & $\underline{-0.09 \pm 0.04(0.03)}$ \\
\hline Story Recall & $-0.16 \pm 0.24(0.49)$ & $-0.5 \underline{5} \pm 0.26(0.04)$ & $-0.14 \pm 0.05(0.002)$ \\
\hline Visual Learning \& Memory & $-0.0 \underline{6} \pm 0.2 \underline{2}(0.7 \underline{8})$ & $-0.4 \underline{9} \pm 0.25(0.0 \underline{49})$ & $\underline{-0.08 \pm 0.04(0.05)}$ \\
\hline Working Memory & $-0.15 \pm 0.23(0.5 \underline{1})$ & $-0.2 \underline{6} \pm 0.27(0.3 \underline{4})$ & $\underline{-0.11 \pm 0.04(0.01)}$ \\
\hline Speed \& Flexibility & $-0.3 \underline{9} \pm 0.2 \underline{0}(0.0 \underline{6})$ & $-0.54 \pm 0.2 \underline{4}(0.02)$ & $\underline{-0.06 \pm 0.04(0.11)}$ \\
\hline
\end{tabular}

Linear mixed model, adjusting for age, gender, practice effects, and race/ethnicity, and accounting for within-family (sibling) correlations and within-individual correlations from up to 10 years of follow up. ${ }^{a}$ Linear mixed model, adjusting for gender and race/ethnicity, and accounting for within-family (sibling) correlations. 
Figure 1. Mean Adjusted Cognitive Function by Risk Allele Carrier Status. Adjusted (for age, gender, practice effects, and race/ethnicity) mean $z$ scores for the six cognitive factors for TREM2 R47H (T allele) carriers (light gray), PLD3 V232M (A allele) carriers (medium gray), $A P O E \& 4$ heterozygotes (dark gray), $A P O E \& 4$ homozygotes (very dark gray), and non-carriers of any of these three risk variants (white). $Z$ scores were standardized ( N $[0,1])$, using means and standard deviations obtained from the whole sample at baseline. Error bars indicate standard error of the mean. 


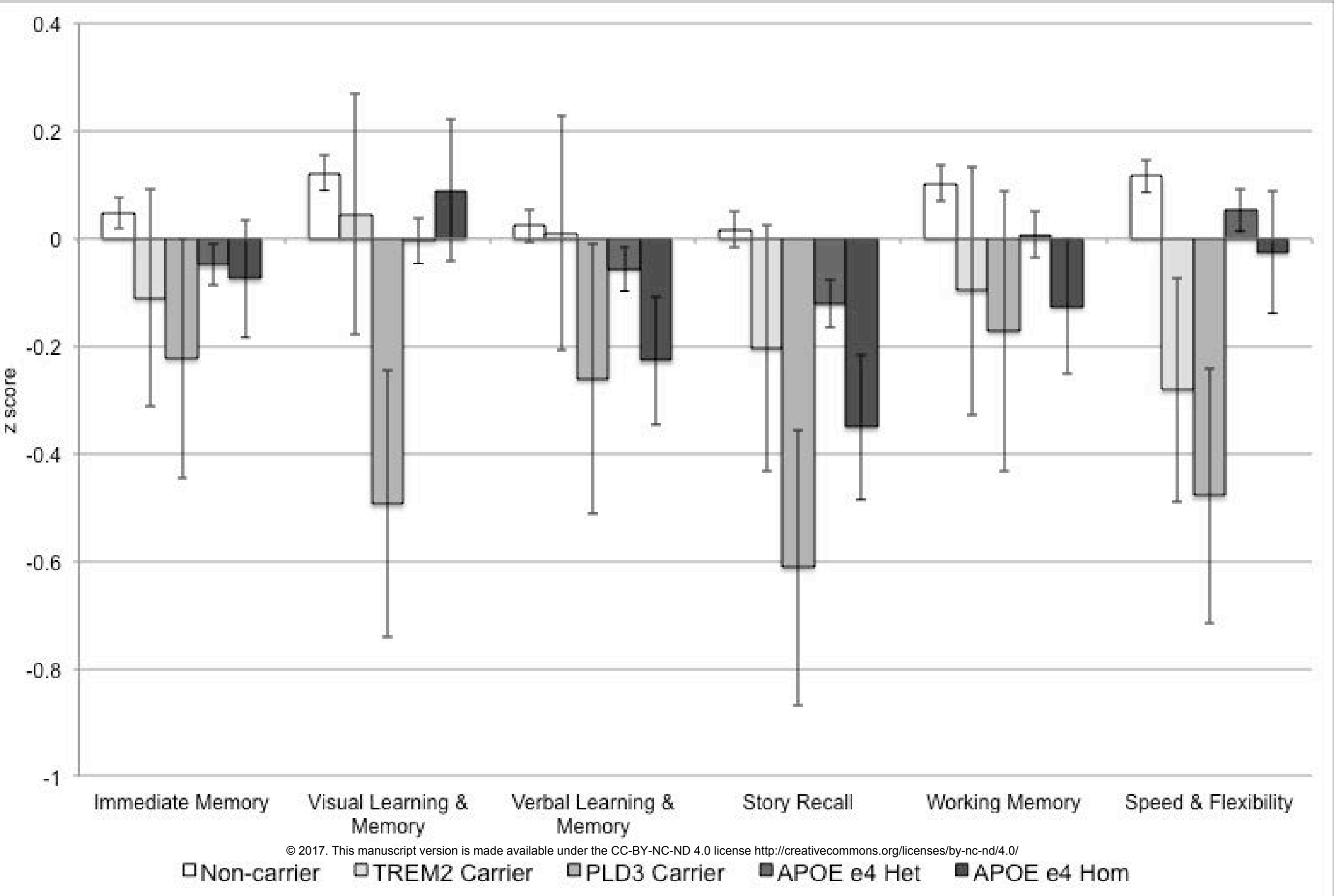

